\title{
Real-World Patient Experience of Switching Biologic Treatment in Inflammatory Arthritis and Ulcerative Colitis - A Systematic Literature Review
}

This article was published in the following Dove Press journal: Patient Preference and Adherence

\author{
Karin Luttropp (iD) \\ Johan Dalén' \\ Axel Svedbom ' \\ Mary Dozier ${ }^{2}$ \\ Christopher M Black (D) ${ }^{3}$ \\ Amy Puenpatom ${ }^{3}$ \\ 'ICON Clinical Research, PIc., Stockholm, \\ Sweden; ${ }^{2}$ ICON Clinical Research, Plc., \\ Boston, MA, USA; ${ }^{3}$ Center for \\ Observational and Real-World Evidence, \\ Merck \& Co., Inc., Kenilworth, NJ, USA
}

Correspondence: Amy Puenpatom Center of Observational and Real-World Evidence, Merck \& Co., Inc., Kenilworth, NJ Tel + I 2673050620

Fax +I 2158504549

Email puenpatom.amy@merck.com
Purpose: To obtain an up-to-date overview of the measurement of patient experience of switching biologic treatment in patients with inflammatory arthritis (IA) or ulcerative colitis (UC). Secondary objectives included summarizing the types of patient-reported outcomes (PROs) used (if any), and related findings; and summarizing medical and non-medical reasons for treatment switch and/or discontinuation.

Methods: A systematic literature review (SLR) was performed, searching Medline and Embase for relevant publications.

Results: In total, 70 relevant publications were identified. While the majority of these reported reasons for switching and/or discontinuing treatment, only four provided information explicitly regarding patient-reported experience of switching biologic treatment. All four utilized ranking tools to assess patient experience of switching biologic treatment. The most common reason for switching and/or discontinuing treatment was loss of efficacy, while the least common reason was patient preference.

Conclusion: Although the number of available treatments in IA and UC have increased, there is a sparsity of information regarding patient-reported experience of switching biologic treatment. Further research regarding patient preference and/or experience would benefit this therapeutic area and help guide treatment choices.

Keywords: arthritis, colitis, ulcerative, biological products, patient reported outcome measures, treatment switch

\section{Introduction}

Ulcerative colitis (UC) and inflammatory arthritis (IA; including rheumatoid arthritis [RA] and spondyloarthropathies [SpA], the latter comprising ankylosing spondylitis [AS] and psoriatic arthritis [PsA]) are conditions for which biologics and novel small molecules have revolutionized treatment. ${ }^{1}$

The growing treatment armamentarium results in an increase in treatment switches among patients with UC and IA. Previously, patients have transitioned between treatments with different modes of action (MoA) - a phenomenon also known as swapping $^{2}$ - and between different treatments with the same MoA (also known as cycling). With the availability of biosimilars, a new type of treatment transition has been introduced: transitioning between different brands of the same medication. This type of transition is expected to increase the rate of switching further as more biosimilar treatments become available to a larger number of patients. Indeed, a substantial proportion of the estimated cost savings from biosimilar introduction is expected to 
be realized through patients transitioning from more expensive originator products to less expensive biosimilars. ${ }^{3,4}$

Previous studies have reported that reduced persistence with biologic treatment is associated with increased costs. $^{5-7}$ In addition, treatment persistence may also be considered as a proxy for safety and efficacy with treatment, as well as patient satisfaction. ${ }^{8-10}$ In line with this view, several studies have reported that biologic treatment properties such as administration route and dosing frequency have an impact on patient preference, and by extension, persistence and adherence with treatment. ${ }^{11,12}$ Worsened adherence to treatment, in turn, decreases treatment efficacy and affects clinical outcomes. ${ }^{11}$

Real-world effectiveness of novel systemics and biologics in UC and IA have been studied extensively and systematic reviews on the subject exist. ${ }^{13}$ However, few studies have described the patient experience of treatment transitions, and to the best of our knowledge, no review of such data has been published. Better understanding of the patient expectations may allow for improved clinical decisionmaking and better outcomes. To this end, we performed a systematic review of real-world and observational studies with two objectives: i) To describe the patient experience of transitioning between different biologic treatments for IA or UC and ii) To summarize reported reasons for treatment switching and discontinuation.

\section{Materials and Methods}

\section{Literature Search and Study Eligibility}

\section{Criteria}

The literature search was performed on October 25th, 2018 in Medline and Embase via Ovid as well as in relevant conference databases (United European Gastroenterology [UEG] week; European Crohn's and Colitis Organisation [ECCO]; Digestive Disease Week [DDW]; European League Against Rheumatism [EULAR]; American College of Rheumatology [ACR]; and The Professional Society for Health Economics and Outcomes Research [ISPOR]). The full search strings are available in Supplementary Tables 1-3. An overview of eligibility criteria for study inclusion according to the Population, Interventions, Comparators, Outcomes, and Study design (PICOS) approach can be seen in Table 1. Any publication failing to meet either of these eligibility criteria was excluded, with the reason for

Table I Study Eligibility Criteria

\begin{tabular}{|c|c|c|}
\hline & Inclusion Criteria & Exclusion Criteria \\
\hline Population & $\begin{array}{l}\text { - Adult patients ( } \geq 18 \text { years) with IA } \\
\text { - Adult patients ( } \geq 18 \text { years) patients with UC }\end{array}$ & $\begin{array}{l}\text { - Pediatric patients } \\
\text { - Studies with fewer than } 20 \text { patients }\end{array}$ \\
\hline Intervention & $\begin{array}{l}\text { Switching from biologic to biologic; from biologic to biosimilar; from } \\
\text { biosimilar to biologic }\end{array}$ & Studies without biologic or biosimilar treatment \\
\hline Comparators & No restrictions & No restrictions \\
\hline Outcomes & $\begin{array}{l}\text { Studies reporting reasons for switching and/or discontinuing treatment } \\
\text { as noted by: } \\
\text { - HCP } \\
\text { - Patient (PRO) }\end{array}$ & $\begin{array}{l}\text { No PROs and/or no HCP-reported reasons for } \\
\text { switching and/or discontinuing treatment }\end{array}$ \\
\hline Study design & $\begin{array}{l}\text { All study designs that include real-world data, observational and } \\
\text { interventional studies (prospective/retrospective) }\end{array}$ & $\begin{array}{l}\text { - RCTs } \\
\text { - Editorials } \\
\text { - Guidelines } \\
\text { - Case reports } \\
\text { - Reviews/meta-analyses }\end{array}$ \\
\hline Language & English & All other languages \\
\hline Time period & $\begin{array}{l}\text { - Publication date from Jan Ist, } 2013 \text { to present (October 25th, 2018) } \\
\text { - Conference abstracts: from } 2016 \text { to present* }\end{array}$ & $\begin{array}{l}\text { - Publications before } 2013 \\
\text { - Conference abstracts before } 2016\end{array}$ \\
\hline $\begin{array}{l}\text { Geographic } \\
\text { scope }\end{array}$ & $\begin{array}{l}\text { - Europe } \\
\text { - North America }\end{array}$ & Continents other than Europe or North America \\
\hline
\end{tabular}

Note: *Only most recent conference searched.

Abbreviations: HCP, healthcare professional; IA, inflammatory arthritis; PRO, patient-reported outcome; RCT, randomised controlled trial; UC, ulcerative colitis. 
exclusion listed (eg, not meeting the criteria for Population, Intervention, Outcomes, etc.) as shown in Figure 1. To restrict the scope to biologics and biosimilars with similar formulation and dosage, the literature search was limited to European and North American studies. The search was restricted to studies published in English.

\section{Study Screening and Data Extraction}

Publications identified from the Ovid and conference database searches were entered in an abstract screening sheet following the removal of duplicates using EndNote X8.2. This study was conducted in accordance with the Preferred Reporting Items for Systematic Reviews and MetaAnalyses (PRISMA) guidelines. ${ }^{14}$ Where several publications reported results for the same patient population, the publication reporting the most information on patient population and/or outcomes of interest was included.

We developed a data extraction file containing information obtained from the identified publications, including underlying studies, patient populations, treatment switch types, and outcomes of interest. Data on the reported switches were extracted and sorted in terms of first, second, and (if applicable) third biologic in a given sequence, including data on whether the biologic was a biosimilar or originator product. To describe the patient experience and reasons for switching treatments, we extracted data on three outcomes: (1) Patient-reported data directly describing the experience of a switch; (2) Patient-reported data indirectly describing the experience of a switch (ie, patient-reported outcomes (PROs) reported before and/or after a treatment switch); and (3) Investigator-reported data on the reason for switch/discontinuation. A full list of data extraction variables can be found in Supplementary Table 4.

\section{Risk of Bias Assessment}

The risk of bias of the included publications was assessed using the Newcastle-Ottawa scale (NOS) for cohort studies. ${ }^{15}$ Typically, risk of bias is not assessed for conference abstracts due to the limited amount of information; however, these were nonetheless included since the majority of publications were only available in abstract format. In addition, minor modifications were made to the assessment template to maintain relevance for the included studies and the primary objective of the current review, as shown in

Included studies $(n=1,781)$

- MEDLINE/EMBASE $(n=1,546)$

- Conference databases $(n=235)$

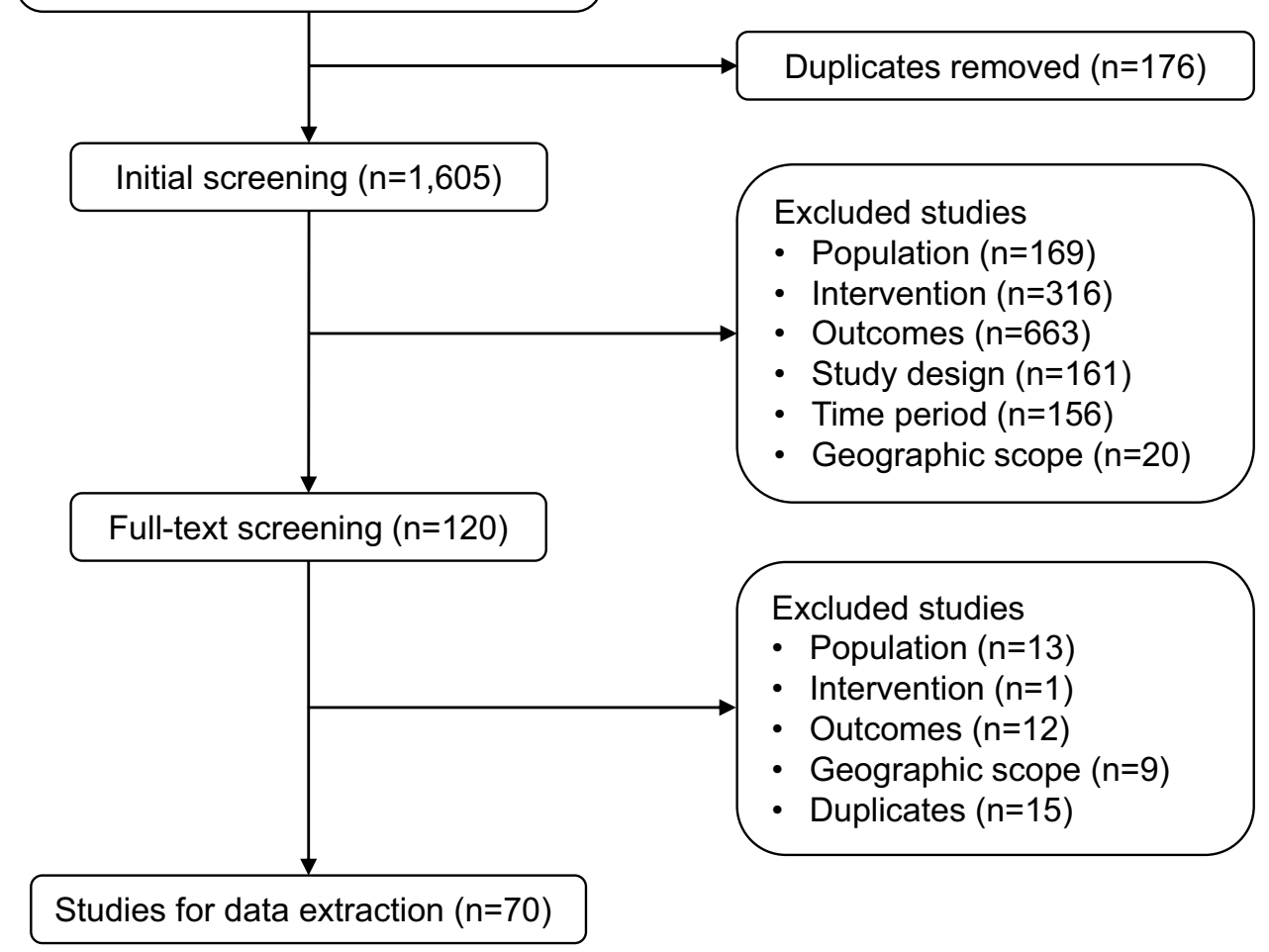

Figure I PRISMA study selection flowchart. 
Supplementary Table 5. Categories "Selection of the nonexposed cohort", "Demonstration that outcome of interest was not present at start of study", and "Was follow-up long enough for outcomes to occur?" were all set as not applicable (NA). Consequently, the minimum score for any publication was 0 (indicating a high risk of bias), while the maximum possible score was 6 (indicating a low risk of bias). It is also worth noting that all studies relevant to the primary objective of the current review were necessarily designed as self-assessment or self-reported studies; hence, all of them received 0 points in the "Assessment of outcome" category. Owing to the large proportion of conference abstracts with insufficient information, as well as to the built-in low score in the NOS for studies utilizing a selfreported approach when measuring outcomes, we decided not to exclude any studies from the current review based on their risk of bias assessment score.

\section{Results}

\section{Identified Studies}

In total, the Ovid and conference database searches generated 1781 hits. Figure 1 illustrates the selection process through a PRISMA flow chart. Following title/abstract (initial) screening and full-text screening, 70 studies were selected for inclusion.

\section{Study Characteristics}

Of the 70 included studies, 19 were full-text articles, ${ }^{7,16-33}$ while 51 were conference abstracts. ${ }^{34-84}$ Study characteristics are described in Supplementary Table 6. 28 studies were

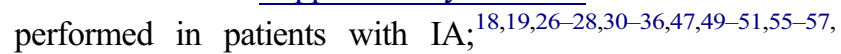

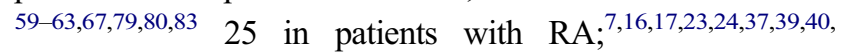
$42-45,53,54,58,66,68,70,73-78,845$ in patients with AS; ${ }^{21,25,46,48,65} 4$ in patients with PsA; $;^{41,64,71,81} 4$ in patients with $U C ;{ }^{22,69,72,82} 2$ in patients with IBD (with results reported separately for UC), ${ }^{38,52}$ and one in patients with SpA. ${ }^{29}$ Most studies were retrospective $(n=37)$, while 28 were prospective and one was cross-sectional. Four studies did not report the study design. A majority of studies were from various countries in Europe $(\mathrm{n}=61)$, while nine studies were from North America (including Canada, Mexico, and USA).

\section{Patient Characteristics}

In studies investigating IA patient populations, the years of data collection ranged between 2000 and 2018, with a mean number of patients of 494 (range: 27-9139) and an average maximum follow-up time of 31.3 months (range: 6-200). On average, $70 \%$ of patients were female, mean age was 53.5 years (range: 27-68), and mean disease duration was 11.1 years (range: $4.3-19.2$ ).

In the studies including patients with UC, the years of data collection ranged between 2009 and 2016, with a mean of 126 patients (range: 27-321) and an average maximum follow-up time of 21.2 months (range: 12-26). On average, $47 \%$ of study participants were female, mean age was 45 years (range: 44-46), and mean disease duration was 10.6 years.

\section{Reported Switches}

All studies included in this review reported the flow of patients between biologic treatments. Of the included studies investigating PROs and/or reasons for treatment switching and/or discontinuation among patients with IA, 24 reported relevant outcomes for one treatment only; 23 studies included two treatments in the sequence; and 17 studies included three treatments.

For UC, four studies only included one treatment in the sequence, while two studies reported treatment sequences of two treatments. An overview of the treatment sequences and specific treatment types is shown in Figure 2, in which the types of treatment in each part of the sequence are listed.

The most common treatment transition sequence was from a tumor necrosis factor inhibitor( TNFi) biologic (ie, adalimumab $\left[\mathrm{Humira}^{\circledR}\right]$, certolizumab pegol [Cimzia ${ }^{\circledR}$ ], etanercept $\left[\right.$ Enbrel $\left.^{\circledR}\right]$, golimumab [Simponi $\left.{ }^{\circledR}\right]$, or infliximab $\left[\right.$ Remicade $\left.^{\circledR}\right]$ ) to a biosimilar (ie, Benepali $/ \mathrm{SB} 4^{\circledR}$ or Inflectra/Remsima/CT-P13 ${ }^{\circledR}$ ). Non-TNFi biologic treatments included abatacept, anakinra, rituximab, tocilizumab, ustekinumab, and vedolizumab, while non-TNFi non-biologic treatments comprised novel small molecule tofacitinib.

Of the 17 studies including three treatments in the sequence, 12 report patients switching back from the second treatment to the first treatment of the sequence (so-called "back-switches"). Among these 12 studies, the "back-switch" proportion ranged from $1 \%$ to $26 \%$ of patients, where the most common type of switch was from the biosimilar Benepali/SB4 ${ }^{\circledR}$ to the originator Enbrel $^{\circledR}$ (7 of 12 studies).

\section{Directly Reported Patient Experience of Switching}

Four studies on patients with IA presented direct, patientreported data on patient experience of switching treatment. ${ }^{27,36,57,77}$ All four studies deployed a ranking 

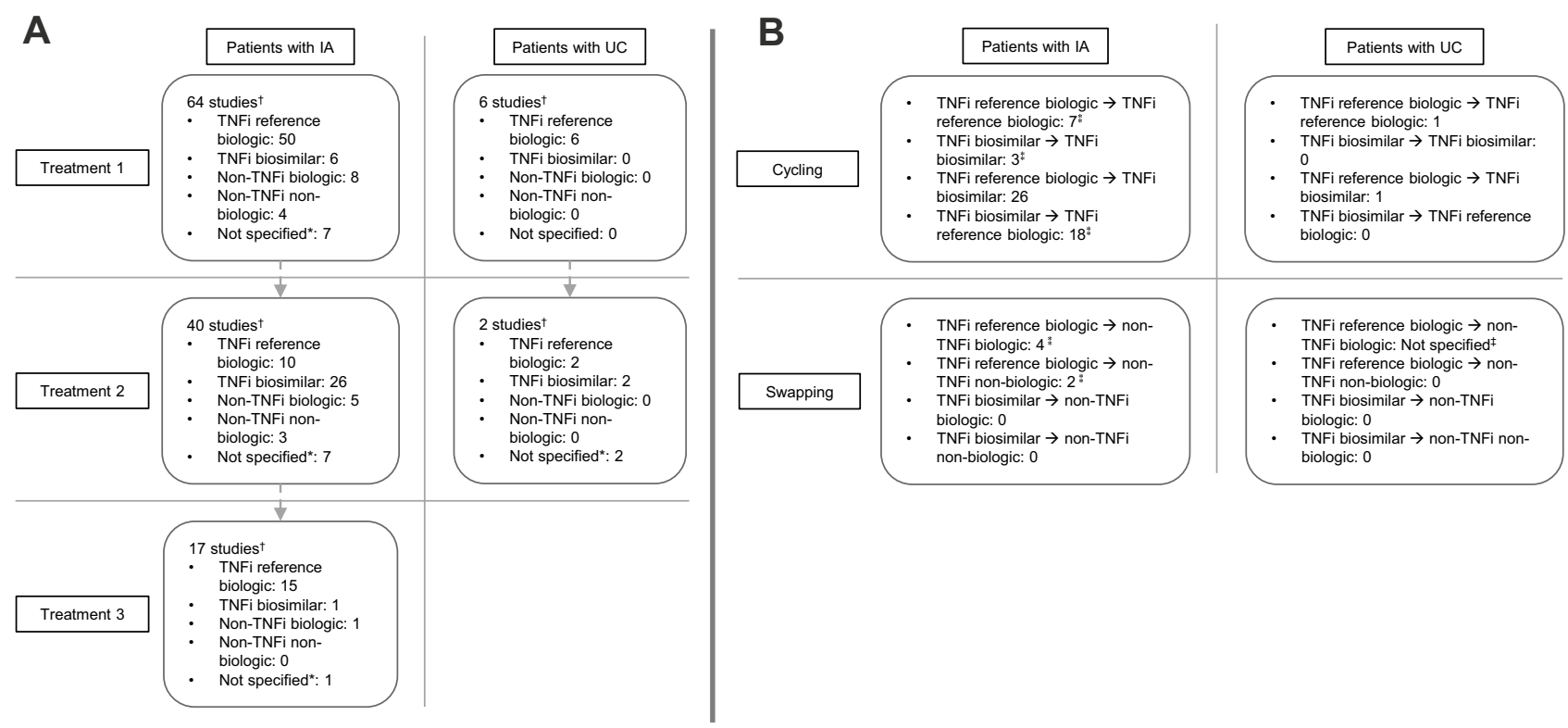

Figure 2 Treatment sequences of included studies. (A): Distribution of treatment types by position in treatment sequence in patients with IA and UC, respectively. (B): The number of studies reporting treatment transitions in patients with IA and UC, respectively.

Notes: 'Some studies include more than one treatment type for each part of the sequence; hence, at each part of the sequence, the number of treatment types is greater than the number of studies. *Includes "Biologic therapy", "TNFi", and "bDMARD". *Includes treatment switching between first and second treatment, and between second and third treatment, in the sequence, respectively. "Second treatment type stated as "biologic therapy" only.

Abbreviations: bDMARD, biological disease-modifying antirheumatic drug; IA, inflammatory arthritis; TNFi, tumor necrosis factor inhibitor; UC, ulcerative colitis.

tool, the results of which are summarized in Table 2. While the ranking categories used differed between studies, the majority of patients reported a neutral or positive switching experience across studies. In addition to the experience of switching, Scherlinger et al (2018) also report that $15 \%$ of patients felt pressured to accept the switch; ${ }^{27}$ however, it is not reported how this subset of patients eventually experienced the actual switch. No study on patients with UC presented data on patient experience from switching.

Table 2 Patient Experience of Switching

\begin{tabular}{|c|c|c|c|c|c|c|c|c|c|}
\hline \multirow{3}{*}{$\begin{array}{l}\text { Author, Year } \\
\text { Attipoe } 2018^{36}\end{array}$} & \multirow{3}{*}{$\begin{array}{l}\text { Switch } \\
\text { ETA biologic } \rightarrow \\
\text { ETA biosimilar }\end{array}$} & \multirow{3}{*}{$\begin{array}{l}\text { Patients } \\
\text { (n) } \\
107\end{array}$} & \multirow{3}{*}{$\begin{array}{l}\text { Indication } \\
\text { AS: II\% } \\
\text { PsA: } 16 \% \\
\text { RA: } 68 \%\end{array}$} & \multirow{3}{*}{$\begin{array}{l}\text { Country } \\
\text { UK }\end{array}$} & \multicolumn{5}{|c|}{ Patient-Reported Switching Experience } \\
\hline & & & & & Excellent & Very good & Satisfactory & Poor & $\begin{array}{l}\text { Very } \\
\text { poor }\end{array}$ \\
\hline & & & & & \multicolumn{2}{|l|}{$45 \%$} & $44 \%$ & \multicolumn{2}{|l|}{$9 \%$} \\
\hline \multirow{2}{*}{$\begin{array}{l}\text { Scherlinger } \\
2018^{27}\end{array}$} & \multirow[t]{2}{*}{ Enbrel $\rightarrow$ SB4 } & \multirow[t]{2}{*}{$52 *$} & \multirow{2}{*}{$\begin{array}{l}\text { RA: } 38 \% \\
\text { SpA (incl AS, PsA, } \\
\text { and SAPHO): } 62 \%\end{array}$} & \multirow[t]{2}{*}{ France } & \multicolumn{5}{|l|}{ Good } \\
\hline & & & & & \multicolumn{5}{|l|}{$86 \%$} \\
\hline \multirow[t]{2}{*}{ Shah $2018^{77}$} & \multirow[t]{2}{*}{$\begin{array}{l}\text { ETA biologic } \rightarrow \\
\text { ETA biosimilar }\end{array}$} & \multirow[t]{2}{*}{155} & \multirow[t]{2}{*}{ RA } & \multirow[t]{2}{*}{ UK } & Pleased & Indifferent & Not sure & $\begin{array}{l}\text { Not } \\
\text { pleased }\end{array}$ & $\begin{array}{l}\text { No } \\
\text { answer }\end{array}$ \\
\hline & & & & & $43 \%$ & $7 \%$ & $8 \%$ & $23 \%$ & $18 \%$ \\
\hline \multirow[t]{2}{*}{ Hoque $2018^{57}$} & \multirow{2}{*}{$\begin{array}{l}\text { ETA biologic } \rightarrow \\
\text { ETA biosimilar }\end{array}$} & \multirow[t]{2}{*}{94} & \multirow[t]{2}{*}{$\mathrm{RA} / \mathrm{Ps} / \mathrm{SpA}$} & \multirow[t]{2}{*}{ UK } & \multicolumn{5}{|c|}{ No problem with switch } \\
\hline & & & & & \multicolumn{5}{|l|}{$62 \%$} \\
\hline
\end{tabular}

Note: *44 patients switched treatment from Enbrel to SB4.

Abbreviations: AS, ankylosing spondylitis; ETA, etanercept; PsA, psoriatic arthritis; RA, rheumatoid arthritis; SAPHO, synovitis-acne-pustulosis-hyperostosis-osteitis syndrome; SpA, spondyloarthritis; UK, United Kingdom. 


\section{Indirectly Reported Patient Experience of Switching}

Among the studies including patients with IA, 21 studies

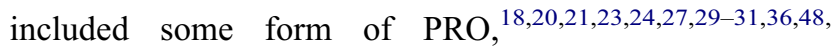
$49,54,57,59,65,75,77,78,80,84$ of which 10 studies reported

PROs prior to the switch only and therefore did not provide any information on the patient experience of switching treatment. ${ }^{20,21,23,24,29-31,49,59,78}$ The PRO measurement tools used are summarized in Figure 3. The most commonly used tool was the Health Assessment Questionnaire (HAQ) (12 studies), ${ }^{18,20,23,24,31,48,49,54,65,75,77,84}$ while the least common measurement methods were Routine Assessment of Patient Index Data 3 (RAPID3) and Treatment Satisfaction Questionnaire for Medication (TSQM), each of which were used in one study only. ${ }^{48}$ No study on patients with UC presented data on PROs before or after treatment switch.

Among the studies reporting PROs before and after treatment switch, Forejtova 2017 reported a decrease in post-switch HAQ scores compared to pre-switch (baseline) scores, ${ }^{48}$ while Haugeberg 2018 reported a slight increase; ${ }^{54}$ none of the changes in HAQ were statistically significant. Glintborg 2017, meanwhile, reported an unchanged mean HAQ score over time. ${ }^{18}$ Similarly, a post-switch visual analogue scale (VAS) score increase was reported by Haugeberg 2018, ${ }^{54}$ while Forejtova 2017 reported a decrease. ${ }^{48}$ Overall, patient global assessment (PGA) scores were mostly stable as reported by Glintborg 2017 and Valido 2018, ${ }^{18,80}$ although a slight increase was observed for patients with PsA in the former study. Zengin 2018 reported a statistically significant decrease in mean PGA score at week 60 compared to baseline. ${ }^{84}$

\section{Investigator-Reported Reason for Switching}

Investigator-reported reasons for patients switching were reported in 20 studies; 19 of these included patients with IA, while one included patients with UC. Reasons for treatment discontinuation were provided in 46 studies, 40 of which were performed in IA patient populations while the remaining six included patients with UC. The results from these studies are summarized in Table 3. Overall, the most common reason for switching or discontinuing treatment was loss of efficacy, while the least common reason was patient preference. Of the four studies listed in Table 2 reporting direct patient experience of switching treatment, two reported reasons for switching back to the originator biologic from the etanercept biosimilar; in both of these, the most common reason was adverse events. ${ }^{27,77}$ These two studies are included in Table 3.

\section{Risk of Bias Assessment}

The detailed results of the risk of bias assessment are provided as a supplementary spreadsheet (Supplementary Table 7). An overview of the scores is shown in Figure 4.

The scores for the included full-text publications ranged between 3 and 6; publications scoring 0 , 1, or 2 - indicating high risk of bias - were all conference abstracts, for which the limited amount of information resulted in a reduced score. Among the four publications reporting patient experience with switching, two publications received a score of $2,3^{36,57}$ one

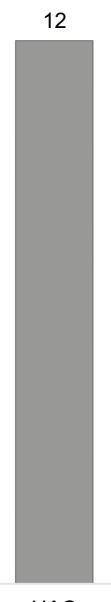

HAQ

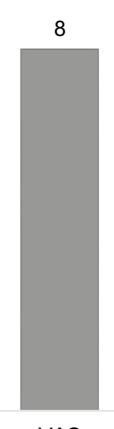

VAS

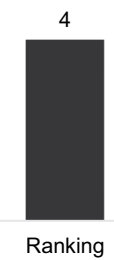

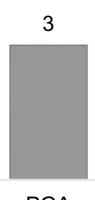
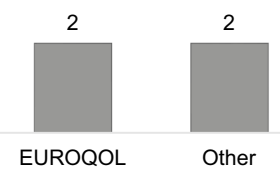

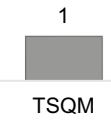

Figure 3 Patient-reported outcome measurement tools used. The number above each bar denotes the number of studies using each particular PRO measurement tool. The four studies reporting patient experience of switching treatment ("Ranking” bar) are highlighted in dark grey.

Abbreviations: HAQ, Health Assessment Questionnaire; VAS, Visual Analogue Scale; PGA, Patient Global Assessment; RAPID3, Routine Assessment of Patient Index Data 3; TSQM, Treatment Satisfaction Questionnaire for Medication. 
Table 3 Reasons for Switching and/or Discontinuing Biologic Originator or Biosimilar Treatment

\begin{tabular}{|l|l|l|l|l|l|}
\hline & Adverse Events & Loss of Efficacy & Remission & Patient Preference & Other \\
\hline Reason for Switching Treatment & & & & & \\
Unweighted mean & $23 \%$ & $52 \%$ & N/A & $14 \%$ & $34 \%$ \\
Median & $22 \%$ & $53 \%$ & N/A & $7 \%$ & $34 \%$ \\
Range & $2-63 \%$ & $2.5-98 \%$ & N/A & $1.9-44 \%$ & $5-67 \%$ \\
\hline Reason for Discontinuing Treatment* & & & & & $10 \%$ \\
Unweighted mean & $25 \%$ & $48 \%$ & $10 \%$ & $9 \%$ & $18 \%$ \\
Median & $23 \%$ & $50 \%$ & $4 \%$ & $4-16 \%$ & $2-55 \%$ \\
Range & $4.4-77 \%$ & $6.3-92 \%$ & $0-52 \%$ & & \\
\hline
\end{tabular}

Note: *These data may or may not include patients switching treatment; not always evident from the reported information.

Abbreviation: N/A, not applicable.

a score of $3 ;^{27}$ and one a score of 4 points, ${ }^{77}$ respectively; however, it is worth noting that, with the exception of Scherlinger $2018,{ }^{27}$ all were conference abstracts.

No publications were excluded as a result of the risk of bias assessment; this is due to the relatively large number of conference abstracts, indicating that the low scores found for some publications are likely to be due to missing information rather than true methodological or reporting flaws.

\section{Discussion}

This study systematically reviewed the literature on the patient experience of switching biologic treatment in IA and UC. One of the main findings is that patient perspective on switching is poorly understood, with only four studies explicitly reporting patients' direct experience of switching. These four studies utilize a ranking exercise with slightly varying categories to assess the switching experience among the patient population. However, the scales used are not standardized and the number of categories differ between studies - Scherlinger et al (2018) ${ }^{27}$ and Hoque et al $(2018)^{57}$ in particular only report the proportion of patients in the "Good" and "No problem with switch" category, respectively. The relatively sparse information provided is likely related to the fact that of

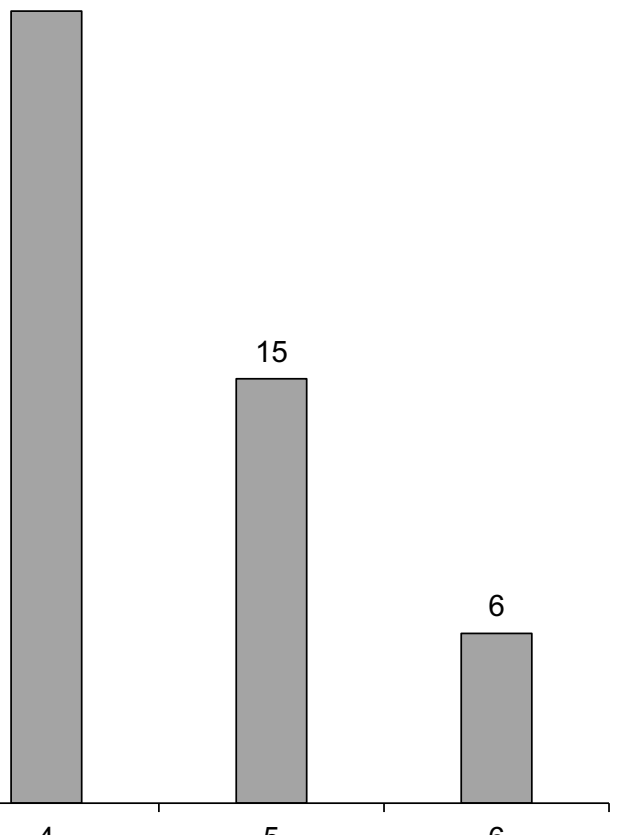

$0 \longdiv { 0 }$

1

2

3

5

6

Figure 4 Risk of bias assessment scores. The number shown above each bar denotes the number of publications receiving a particular score. 
these four publications, Scherlinger et al $(2018)^{27}$ was a full-text article while the remaining three were conference abstracts. Given the limited amount of available data regarding patient experience of switching, as well as the diversity in measurement methods between the studies that do report this outcome, the current literature does not allow for a meaningful comparison across studies.

A number of publications include indirect information pertaining to the patient experience of switching by reporting PROs before and after a treatment switch. While it is impossible to isolate and quantify the potential direct impact of the treatment switch on observed changes in these PROs, it can be noted that the results were heterogenous: A few studies reported no change, or an improvement, in HAQ, VAS, and PGA scores following the switch, while others showed the opposite. One possible reason for this heterogeneity may be differences in followup time, which was reported in some, but not all, publications.

A majority of the studies included in this review provided investigator-reported reasons for switching and/or discontinuing treatment. While these do not provide the same level of insight into the patient experience of switching as the studies reporting PROs do, they nonetheless serve to illustrate the more common reasons underlying changes in treatment. Notably, the least common reason for switching or discontinuing treatment was patient preference, which is in line with the finding that numerous studies included in this review state that the initial switch, in which patients cycle from originator to biosimilar products, was due to non-medical reasons and mandated by healthcare payers. ${ }^{18,31,32,43,44,49,50,54,55,62,80}$ This is in contrast to switching to a treatment with another MoA, which generally occurs due to medical reasons ${ }^{2}$ and is less related to mandates issued by payers. In this context, it is of interest to note that an overall originator-to-biosimilar switching strategy has been recommended by several healthcare authorities ${ }^{3,85}$ and that this review found that the most commonly cited reason for switching back to the originator drug from biosimilar treatment was adverse events. $^{27,77}$ This is in line with the observed association of treatment persistence with the effectiveness, safety, and patient satisfaction with treatment; ${ }^{8-10}$ maintaining patient persistence with the prescribed therapy is of interest from a payer perspective, as switching treatment has been associated with increased costs. ${ }^{5-7}$

While the number of studies reporting patient experience of switching was low, they indicate that a majority of patients have a positive or neutral switching experience. However, the reasons for the dissatisfaction reported among a minority of patients are not further explored.

The proportion of patients who switch back to their original treatment ("back-switch" proportion) ranged from a low $1 \%{ }^{43}$ to a quarter of the patients $(26 \%) .{ }^{63}$ Elucidating the reasons underlying this difference is of interest to promote an agreeable switching experience for the patients, thereby minimizing the risk of performing additional switches. This is of particular importance, not just from a cost perspective, but also since payer-mandated switches from originator to biosimilar treatments are being implemented by various healthcare authorities. ${ }^{3,85}$ Increased educational and informational efforts provided by healthcare professionals $(\mathrm{HCP})$ prior to the treatment transition are doubtlessly important to increase patient satisfaction. This fact is highlighted by the finding reported by Attipoe et al, in which $21 \%$ of patients stated that their transition experience would have improved if having been given more information about the biosimilar treatment they were being switched to. ${ }^{36}$ Furthermore, Al Tabaa et al conclude that the likelihood of patients transitioning to a biosimilar treatment was mainly related to the behavior of the physicians; and that, when using an open study design, a larger proportion of patients transitioning to a biosimilar treatment complained of lower efficiency and/or a worse safety profile. ${ }^{34}$ Scherlinger et al also suggest that negative patient perceptions of biosimilars impact the persistence with biosimilar treatment, as shown by the lack of objective clinical disease activity among a large proportion of patients who requested to be transitioned back to the originator treatment. ${ }^{26}$ Taken together, this points to the importance of considering a nocebo effect when investigating patient satisfaction with treatment transition. While factors impacting patient experience of switching biologic treatment were not the primary objective of the current review, it remains an important area for future research. As the number of publications investigating patient-reported experiences continue to increase, the amount of data available will consequently allow for a statistically sound analysis to be conducted.

Furthermore, while several studies included information regarding the treatment history of patients (ie, naïve to, or experienced with, biologic treatment), none reported PROs related to switching experience by treatment line. As it is conceivable that previous experience with biologic treatment may have an impact on the experience of switching, stratifying analyses by treatment line should be an avenue of interest in future studies. 
The use of treatment persistence as a proxy for efficacy and/or safety of the prescribed therapy is also highlighted by the finding that across the studies included in this review, loss of efficacy or adverse events were the most common reasons for switching or discontinuing treatment.

The current study has some limitations. Firstly, the number of conference abstracts compared to full-text articles is relatively large, which poses a restriction on the amount of available information for each study. Secondly, the limited data availability also meant that a meta-analysis was not feasible. As the four studies providing information regarding patient-reported experience of switching all used different ranking scales, this further hindered the possibility of performing a meta-analysis. The language restriction (English only) is also likely to have resulted in the exclusion of relevant studies; however, as the geographic scope was limited to Europe and North America, any studies performed in patient populations from other continents would have been excluded. It is also worth noting that the three studies by Glintborg et al all use the DANBIO registry and that the overlap of patients is therefore likely to be considerable. ${ }^{18,49,50}$ This is especially pertinent for the two conference abstracts, both of which focus on patients treated with etanercept. However, as the population size, patient baseline characteristics, and number of treatment switches differ between the two publications, both were included as it was not possible to discern the amount of overlap. Similarly, the two publications by DeCock et $\mathrm{al}^{43,44}$ investigate the same database and indication; however, since the reported variables available for extraction differed somewhat, the studies were considered to overlap and both were therefore included.

In summary, while patient experience and satisfaction are of great importance to achieve successful treatment outcomes, the current review of studies reporting patient experience of switching biologic and/or biosimilar treatment indicates that it is an area in need of further exploration. In addition, while ranking exercises may be an appropriate tool to investigate patient-reported experience of switching treatment, the research topic would benefit from the use of more standardized, or translatable, assessments to enable meta-analyses or easy comparison between studies.

\section{Conclusion}

This systematic literature review illustrates the current sparsity of information regarding patient-reported experience of switching biologic and/or biosimilar treatment in
IA and UC populations from real-world studies. Since patient preference and experience influence adherence and persistence with treatment, thereby affecting the clinical response, these factors should be considered in the treatment decision process. As the number of available treatments continue to increase, further research regarding patient preference and/or experience would benefit this therapeutic area.

\section{Acknowledgment}

This work was funded by Merck Sharp \& Dohme Corp., a subsidiary of Merck \& Co., Inc., Kenilworth, NJ, USA.

\section{Disclosure}

$\mathrm{KL}$, JD, AS, and MD conducted this work as part of their employment with ICON plc. CMB and AP are employees of Merck Sharp \& Dohme Corp., a subsidiary of Merck \& Co., Inc., Kenilworth, NJ, USA. The authors report no other conflicts of interest in this work.

\section{References}

1. Stevens SRC. History of development of TNF inhibitors. In: Weinberg JM, editor. TNF-Alpha Inhibitors. Milestones in Drug Therapy. Basel: Birkhäuser; 2006;9-22.

2. Todoerti M, Favalli EG, Iannone F, et al. Switch or swap strategy in rheumatoid arthritis patients failing TNF inhibitors? Results of a modified Italian Expert Consensus. Rheumatology (Oxford). 2018;57(57 Suppl 7):vii42-vii53. doi:10.1093/rheumatology/key195

3. NHS England. Commissioning framework for biological medicines (including biosimilar medicines). 2017.

4. Liu Y, Yang M, Garg V, Wu EQ, Wang J, Skup M. Economic impact of non-medical switching from originator biologics to biosimilars: a systematic literature review. Adv Ther. 2019;36:1851-1877.

5. Cannon GW, DuVall SL, Haroldsen CL, et al. Clinical outcomes and biologic costs of switching between tumor necrosis factor inhibitors in US veterans with rheumatoid arthritis. Adv Ther. 2016;33 (8):1347-1359. doi:10.1007/s12325-016-0371-0

6. Meissner B, Trivedi D, You M, Rosenblatt L. Switching of biologic disease modifying anti-rheumatic drugs in patients with rheumatoid arthritis in a real world setting. $J$ Med Econ. 2014;17(4):259-265. doi:10.3111/13696998.2014.893241

7. Rashid N, Lin AT, Aranda G, et al. Rates, factors, reasons, and economic impact associated with switching in rheumatoid arthritis patients newly initiated on biologic disease modifying anti-rheumatic drugs in an integrated healthcare system. J Med Econ. 2016;19 (6):568-575. doi:10.3111/13696998.2016.1142448

8. Aletaha D, Smolen JS. Effectiveness profiles and dose dependent retention of traditional disease modifying antirheumatic drugs for rheumatoid arthritis. An observational study. J Rheumatol. 2002;29 (8):1631-1638.

9. Fries JF. Effectiveness and toxicity considerations in outcome directed therapy in rheumatoid arthritis. $J$ Rheumatol Suppl. 1996;44:102-106.

10. Pincus T, Marcum SB, Callahan LF, et al. Longterm drug therapy for rheumatoid arthritis in seven rheumatology private practices: I. Nonsteroidal antiinflammatory drugs. J Rheumatol. 1992;19 (12):1874-1884. 
11. Barton JL. Patient preferences and satisfaction in the treatment of rheumatoid arthritis with biologic therapy. Patient Prefer Adherence. 2009;3:335-344. doi:10.2147/PPA

12. Zhang M, Brenneman SK, Carter CT, et al. Patient-reported treatment satisfaction and choice of dosing frequency with biologic treatment for moderate to severe plaque psoriasis. Patient Prefer Adherence. 2015;9:777-784. doi:10.2147/PPA.S85773

13. Cohen HP, Blauvelt A, Rifkin RM, Danese S, Gokhale SB, Woollett G. Switching Reference medicines to biosimilars: a systematic literature review of clinical outcomes. Drugs. 2018;78 (4):463-478. doi:10.1007/s40265-018-0881-y

14. Moher D, Liberati A, Tetzlaff J, Altman DG, Group P. Preferred reporting items for systematic reviews and meta-analyses: the PRISMA statement. PLoS Med. 2009;6(7):e1000097. doi:10.1371/ journal.pmed.1000097

15. Wells G, Shea B, O'Connell D. Newcastle-ottawa quality assessment scale-cohort studies. 2012. Available from: http://www.ohri.ca/pro grams/clinical_epidemiology/oxford.asp. Accessed June 15, 2019.

16. Bolge SC, Goren A, Tandon N. Reasons for discontinuation of subcutaneous biologic therapy in the treatment of rheumatoid arthritis: a patient perspective. Patient Prefer Adherence. 2015;9:121-131. doi:10.2147/PPA

17. De Keyser F, Hoffman I, Durez P, et al. Longterm followup of rituximab therapy in patients with rheumatoid arthritis: results from the Belgian MabThera in Rheumatoid Arthritis registry. J Rheum. 2014;41(9):1761-1765. doi:10.3899/jrheum.131279

18. Glintborg B, Sorensen IJ, Loft AG, et al. A nationwide non-medical switch from originator infliximab to biosimilar CT-P13 in 802 patients with inflammatory arthritis: 1-year clinical outcomes from the DANBIO registry. Ann Rheum Dis. 2017;76(8):1426-1431. doi:10.1136/annrheumdis-2016-210742

19. Kadar G, Balazs E, Soos B, et al. Disease activity after the discontinuation of biological therapy in inflammatory rheumatic diseases. Clin Rheumatol. 2014;33(3):329-333. doi:10.1007/s10067-014-2508-3

20. Leon L, Rodriguez-Rodriguez L, Rosales Z, et al. Long-term drug survival of biological agents in patients with rheumatoid arthritis in clinical practice. Scand $J$ Rheumatol. 2016;45(6):456-460. doi:10.3109/03009742.2016.1141979

21. Lorenzin M, Ortolan A, Frallonardo P, Oliviero F, Punzi L, Ramonda R. Predictors of response and drug survival in ankylosing spondylitis patients treated with infliximab. BMC Musculoskelet Disord. 2015;16(1):166. doi:10.1186/s12891-015-0620-4

22. Narula N, Peerani F, Meserve J, et al. Vedolizumab for ulcerative colitis: treatment outcomes from the VICTORY consortium. Am $J$ Gastroenterol. 2018;113(9):1345-1354. doi:10.1038/s41395-0180162-0

23. Neovius M, Arkema EV, Olsson H, et al. Drug survival on TNF inhibitors in patients with rheumatoid arthritis comparison of adalimumab, etanercept and infliximab. Ann Rheum Dis. 2015;74 (2):354-360. doi:10.1136/annrheumdis-2013-204128

24. Oldroyd AGS, Symmons DPM, Sergeant JC, et al. Long-term persistence with rituximab in patients with rheumatoid arthritis. Rheumatology (Oxford). 2018;57(6):1089-1096. doi:10.1093/rheumatology/key036

25. Rusman T, Ten Wolde S, Euser SM, et al. Gender differences in retention rate of tumor necrosis factor alpha inhibitor treatment in ankylosing spondylitis: a retrospective cohort study in daily practice. Int J Rheum Dis. 2018;21(4):836-842. doi:10.1111/1756-185X.13271

26. Scherlinger M, Germain V, Labadie C, et al. Switching from originator infliximab to biosimilar CT-P13 in real-life: the weight of patient acceptance. Joint Bone Spine. 2018;85(5):561-567. doi:10.1016/j.jbspin.2017.10.003

27. Scherlinger M, Langlois E, Germain V, Schaeverbeke T. Acceptance rate and sociological factors involved in the switch from originator to biosimilar etanercept (SB4). Semin Arthritis Rheum. 2019;48 (5):927-932. doi:10.1016/j.semarthrit.2018.07.005
28. Schmitz EMH, Benoy-de Keuster S, Meier AJL, et al. Therapeutic drug monitoring (TDM) as a tool in the switch from infliximab innovator to biosimilar in rheumatic patients: results of a 12-month observational prospective cohort study. Clin Rheumatol. 2017;36 (9):2129-2134. doi:10.1007/s10067-017-3686-6

29. Sepriano A, Ramiro S, van der Heijde D, et al. Effect of comedication with conventional synthetic disease-modifying antirheumatic drugs on retention of tumor necrosis factor inhibitors in patients with spondyloarthritis: a prospective cohort study. Arthritis Rheuma. 2016;68(11):2671-2679. doi:10.1002/art.39772

30. Thomas K, Flouri I, Repa A, et al. High 3-year golimumab survival in patients with rheumatoid arthritis, ankylosing spondylitis and psoriatic arthritis: real world data from 328 patients. Clin Exp Rheumatol. 2018;36(2):254-262.

31. Tweehuysen L, Huiskes VJB, van den Bemt BJF, et al. Open-label, non-mandatory transitioning from originator etanercept to biosimilar SB4: six-month results from a controlled cohort study. Arthritis Rheuma. 2018;70(9):1408-1418. doi:10.1002/art.40516

32. Tweehuysen L, van den Bemt BJF, van Ingen IL, et al. Subjective complaints as the main reason for biosimilar discontinuation after open-label transition from reference infliximab to biosimilar infliximab. Arthritis Rheuma. 2018;70(1):60-68. doi:10.1002/ art.40324

33. Varela H, Villamanan E, Plasencia C, et al. Safety of antitumour necrosis factor treatments in chronic rheumatic diseases: therapy discontinuations related to side effects. J Clin Pharm Ther. 2016;41 (3):306-309. doi:10.1111/jcpt.12393

34. Al Tabaa O, Etcheto A, Miceli-Richard C, Anna M, Dougados M Switch from innovator etanercept to biosimilar etanercept in inflammatory rheumatic diseases: the experience of Cochin University Hospital Paris-France. Paper presented at: Annual European Congress of Rheumatology, EULAR2018, Amsterdam.

35. Alkoky H, Pakozdi A, Tahir H. Benepali switches in clinical practice - a positive single centre experience. Arthritis Rheuma. 2018;70 (Supplement 9):2788-2789.

36. Attipoe L, Patel S, Birt R, Crooks J, Hunt K, Grigoriou A. What factors predict good patient experiences of switching from reference etanercept to an etanercept biosimilar in a south west london general hospital? Rheumatology. 2018;57(Supplement 3):iii63.

37. Baganz L, Meissner Y, Herzer P, et al. Treatment continuation on the etanercept original in comparison with a biosimilar. Arthritis Rheuma. 2018;70(Supplement 9):2789-2790.

38. Bressler B, Greenup AJ, Bassel M, et al. Vedolizumab outcomes in real-world bio-naive ulcerative colitis and Crohn's disease patients (EVOLVE) in Canada: interim results. J Crohn's Colitis. 2018;12 (Supplement 1):S382. doi:10.1093/ecco-jcc/jjx180.673

39. Choquette D, Bessette L, Alemao E, et al. Retention rates of TNF inhibitors and abatacept used as a first biologic DMARD in the treatment of rheumatoid arthritis: 8 years of experience from the Rhumadata registry. J Rheum. 2018;45(7):1053.

40. Choquette D, Bessette L, Haraoui B, et al. Rituximab shows better sustainability than TNF inhibitors when used following initial biologic DMARD failure in the treatment of rheumatoid arthritis: 8 years of real-world observations from the RHUMADATA clinical database and registry. Ann Rheum Dis. 2017;76(Supplement 2):845-846.

41. Conesa Mateos A, Fernandez-Prada M, Exposito-Molinero R, et al. Certolizumab Pegol's effectiveness, retention rate and safety in psoriatic arthritis. Routine clinical practice data. Ann Rheum Dis. 2018;77 (Supplement 2):1579.

42. Curtis JR, Sullivan E, Kershaw J, Blackburn S, Mahajan P, Boklage S. Physician-reported behaviours and treatment trends of tumour necrosis factor inhibitor use: cycling versus switching in five European countries: france, Germany, Italy, Spain and the UK. Ann Rheum Dis. 2018;77(Supplement 2):1385-1386. 
43. De Cock D, Dyball S, Kearsley-Fleet L, Watson K, Hyrich K Profiling rheumatoid arthritis biosimilar switchers: data from the British society for rheumatology biologics register for rheumatoid arthritis. Paper presented at: Annual Conference of the British Society for Rheumatology 2018, Liverpool.

44. De Cock D, Watson K, Hyrich KL. Biosimilars in the UK: early real world data from the british society for rheumatology biologics registers for rheumatoid arthritis. Ann Rheum Dis. 2017;76(Supplement 2):555-556.

45. Dyball S, Hoskins V, Christy-Kilner S, Haque S. Effectiveness and tolerability of benepali in rheumatoid arthritis patients switched from enbrel. Arthritis Rheum Conf. 2017;69(Supplement):10.

46. Exposito-Molinero R, Garcia-Portales R, Lamua-Riazuelo JR, et al. Effectiveness and retention rate of certolizumab pegol in spondyloarthritis. Real life data. Ann Rheum Dis. 2018;77(Supplement 2):1550.

47. Favalli EG, Selmi C, Becciolini A, et al. The 8-year retention rate of the first TNF-inhibitor in the treatment of spondyloarthropathies: real-life data from a multicentric local registries. Ann Rheum Dis. 2016;75(Supplement 2):810. doi:10.1136/annrheumdis-2016-eular. 3404

48. Forejtova S, Zavada J, Szczukova L, Jarosova K, Philipp T, Pavelka K. A non-medical switch from originator infliximab to biosimilar CT-p13 in 36 patients with ankylosing spondylitis: 6-months clinical outcomes from the Czech Biologic registry attra. Arthritis Rheum Conf. 2017;69(Supplement 10).

49. Glintborg B, Omerovic E, Danebod K, et al. One-year clinical outcomes in 1623 patients with inflammatory arthritis who switched from originator to biosimilar etanercept-an observational study from the Danish Danbio registry. Arthritis Rheum Conf. 2017;69 (Supplement 10):1550.

50. Glintborg B, Sorensen IJ, Omerovic E, et al. One-year follow-up of a nationwide cohort of patients with inflammatory arthritis, who switched from originator to biosimilar etanercept, focusing on patients who switched back to originator. An observational Danbio study. Ann Rheum Dis. 2018;77(Supplement 2):595-596.

51. Gonzalez Fernandez CM, Alegre-Sancho JJ, Garcia-Carazo S, et al. Persistence on golimumab as second line biological therapy in patients with spondyloarthritis (axial spondyloarthritis and psoriatic arthritis). Go-beyond, a retrospective study. Ann Rheum Dis. 2018;77 (Supplement 2):1543.

52. Gonzalez Munoza C, Mesonero F, Bargallo A, et al. Efficacy and safety of vedolizumab in inflammatory bowel disease: real-life experience. J Crohn's Colitis. 2018;12(Supplement 1):S486. doi:10.1093/ecco-jcc/jjx180.867

53. Hacioglu A, Hatemi G, Esatoglu SN, et al. Tapering TNF inhibitors in rheumatoid arthritis: A retrospective study. Ann Rheum Dis. 2017;76(Supplement 2):1186.

54. Haugeberg G, Bakland G, Rodevand E, Fevang BT, Diamantopoulos A, Hansen IJW. Drug survival and reason for drop-out in rheumatoid arthritis patients with a nonmedical switch from originator to biosimilar etanercept-preliminary data from a Norwegian multicenter study. Ann Rheum Dis. 2018;77 (Supplement 2):1383.

55. Hendricks O, Horslev-Petersen K. When etanercept switch fails clinical considerations. Arthritis Rheum Conf. 2017;69(Supplement $10)$.

56. Holroyd C, Wallis D, Bennett S, Clayton P, Edwards CJ. Switching from bio-original etanercept to biosimilar etanercept SB4: patient acceptability and outcomes in the real world. Ann Rheum Dis. 2017;76(Supplement 2):1180.

57. Hoque T, Suddle A, Herdman L, Kitchen J. Patient perceptions of switching to biosimilars. Rheumatology. 2018;57(Supplement 3): iii67-iii68.

58. Karakoc Y, Ercan I. Drug survival analysis of tofacitinib in patients with rheumatoid arthritis. Ann Rheum Dis. 2018;77(Supplement 2):1411.
59. Kellner H. High acceptance rate in RA, AS and PsA patients when being started on biosimilar TNF or being switched from the original TNF MAB (remicade, enbrel) - a single center experience. Ann Rheum Dis. 2017;76(Supplement 2):1436.

60. Layegh Z, Ruwaard J, Hebing RC, et al. Efficacious transition from reference product infliximab to the biosimilar in daily practice. Ann Rheum Dis. 2018;77(Supplement 2):1733.

61. Lee SY, Szeto MCH, Galloway JB. Bio-similar to bio-originator switchback: not a reliable quality indicator. Ann Rheum Dis. 2018;77(Supplement 2):1727-1728.

62. Ma J, Petford S, Jones L, Douglas K, John H. Audit of the clinical efficacy and safety of etanercept biosimilar to its product in patients with inflammatory arthritis: experience from a district general hospital in The United Kingdom. Ann Rheum Dis. 2018;77(Supplement 2): 1386 .

63. Madenidou A-V, Jeffries A, Varughese $\mathrm{S}$, et al. Switching patients with arthritis from etanercept (enbrel) to the biosimilar drug, benepali: a single- center retrospective observational study. Paper presented at: American College of Rheumatology, ACR2018, Chicago.

64. Mease P, Liu M, Gershenson B, Hur P, Greenberg J. Discontinuation and switching patterns of tumour necrosis factor inhibitor (TNFi) therapy in TNFi-naive and TNFi-experienced patients with psoriatic arthritis in the US Corrona psoriatic arthritis/spondyloarthritis (PSA/ SPA) registry. Ann Rheum Dis. 2018;77(Supplement 2):382.

65. Mease PJ, Van Der Heijde D, Karki C, Liu M, Park Y, Greenberg JD. Discontinuation of tumor necrosis factor inhibitor therapy in us patients with ankylosing spondylitis: data from the corrona psoriatic arthritis/spondyloarthritis (PSA/SPA) registry. Arthritis Rheum Conf. 2017;69(Supplement):10.

66. Movahedi M, Hepworth E, Mirza R, Cesta A, Larche M, Bombardier C. Time to discontinuation of biologic therapy by mechanism of action in rheumatoid arthritis: results from a rheumatoid arthritis cohort. Arthritis Rheuma. 2018;70 (Supplement 9):624-625.

67. Muskens WD, Rongen-van Dartel SAA, Adang E, Van Riel PL. The influence of switching from etanercept originator to its biosimilar on effectiveness and and the impact of shared decision making on retention and withdrawal rates. Ann Rheum Dis. 2018;77 (Supplement 2):1399.

68. Nolkha N, Sheeran T, Venkatachalam S. Drug survival and efficacy of abatacept in rheumatoid arthritis patients in routine care -7 year experience from a single centre in the United Kingdom. Ann Rheum Dis. 2018;77(Supplement 2):959-960.

69. Orlandini B, Dragoni G, Bagnoli S, Deiana S, MacRi G, Rogai F. Prospective evaluation of clinical efficacy and safety of golimumab in biologic experienced and naive patients with moderate to severe ulcerative colitis: experience from a tertiary referral centre. J Crohn's Colitis. 2017;11(Supplement 1):S284. doi:10.1093/ecco-jcc /jjx002.532

70. Patel D, Ahmed TJ, Levy S, Rajak R, Sathananthan R, Horwood N. Analysis of rheumatoid arthritis patients who failed the switch from originator etanercept to biosimilar etanercept in Croydon. Rheumatology. 2018;57(Supplement 3):iii199.

71. Perez Albaladejo L, Notario Ferreira I, Anon Onate I, et al. Survival at 6 and 12 months of ustekinumab in patients with psoriatic arthritis in conditions of clinical practice. Ann Rheum Dis. 2018;77 (Supplement 2):1591-1592.

72. Ramos L, Hernandez Camba A, De La Barreda R, et al. Clinical outcome with biological therapy in ulcerative colitis: real-world clinical setting from a multi-centre observational study. J Crohn's Colitis. 2018;12(Supplement 1):S504. doi:10.1093/ecco-jcc/jjx180. 906

73. Rolon Campuzano R, Coronel Ale AL, Cerda OL, et al. Patterns of change of a second biological DMARD in a cohort of rheumatoid arthritis patients. J Clin Rheum. 2018;24(3 Supplement 1):S4. doi:10.1097/RHU.0000000000000692 
74. Salmon JH, Letarouilly JG, Coquerelle P, et al. Therapeutic maintenance of abatacept in rheumatoid arthritis: results of the RIC-ABA study (517 patients). Ann Rheum Dis. 2018;77 (Supplement 2):1385.

75. Sari A, Armagan B, Kilic L, et al. Abatacept experience in biologic naive rheumatoid arthritis patients: HUR-BIO real life results. Ann Rheum Dis. 2017;76(Supplement 2):854-855.

76. Sebastiani M, Manfredi A, Iannone F, et al. Early discontinuation of first line biological treatment with etanercept in patients with rheumatoid arthritis: results from the Italian Gisea registry. Ann Rheum Dis. 2018;77(Supplement 2):957.

77. Shah K, Flora K, Penn H. Clinical outcomes of a multi-disciplinary switching programme to biosimilar etanercept for patients with rheumatoid arthritis. Rheumatology. 2018;57(Supplement 3):iii143iii144.

78. Trope S, Thibaud G, Alliot F, Formont D, Krouri S. Quality of life of rheumatoid arthritis patients treated with biologics. Arthritis Rheuma. 2018;70(Supplement 9):1723.

79. Uslu S, Can G, Senel S, et al. The efficacy and drug survival of the biosimilar infliximab (CT-P13) compared to the original reference infliximab in inflammatory rheumatic diseases; results from the turkbio Registry. Paper presented at: American College of Rheumatology, ACR2018, Chicago.
80. Valido A, Silva-Dinis J, Saavedra MJ, Bernardo N, Fonseca JE. Efficacy and cost analysis of a systematic switch from originator infliximab to biosimilar CT-P13 of all patients with inflammatory arthritis from a single centre. Ann Rheum Dis. 2018;77(Supplement 2):1712-1713.

81. Vieira-Sousa E, Eusébio M, Ávila-Ribeiro P, et al. Tumour necrosis factor inhibitors persistence in psoriatic arthritis patients. Paper presented at: Annual European Congress of Rheumatology, EULAR2018, Amsterdam.

82. Viola A, Pugliese D, Renna S, et al. Outcome in ulcerative colitis after switch from subcutaneous anti-TNF to intravenous anti-TNF: A multicentre study. Paper presented at: Conference of European Crohn's and Colitis Organisation 2018, Vienna.

83. Xibille D, Carrillo S, Sicsik S, et al. Preferences in the use of biologic drugs and adverse events in patients with rheumatic disease from a national biologics registry in Mexico. Ann Rheum Dis. 2018;77 (Supplement 2):1377.

84. Zengin B, Inanc N, Akar S, et al. Similar efficacy of tofacitinib on disease activity in rheumatoid arthritis patients with and without previous biologicals; results from the turkbio registry. Ann Rheum Dis. 2018;77(Supplement 2):1401-1402.

85. RADS. The Danish Regions, RADS, Guidelines for Use of Biosimilar Infliximab and Etanercept; 2016.
Patient Preference and Adherence

\section{Publish your work in this journal}

Patient Preference and Adherence is an international, peer-reviewed, open access journal that focusing on the growing importance of patient preference and adherence throughout the therapeutic continuum. Patient satisfaction, acceptability, quality of life, compliance, persistence and their role in developing new therapeutic modalities and compounds to optimize clinical outcomes for existing disease
Dovepress

states are major areas of interest for the journal. This journal has been accepted for indexing on PubMed Central. The manuscript management system is completely online and includes a very quick and fair peer-review system, which is all easy to use. Visit http:// www.dovepress.com/testimonials.php to read real quotes from published authors. 